RESEARCH PAPER

\title{
Tobacco use in popular movies during the past decade
}

\author{
C Mekemson, D Glik, K Titus, A Myerson, A Shaivitz, A Ang, S Mitchell
}

Tobacco Control 2004;13:400-402. doi: 10.1136/tc.2003.007211

\begin{tabular}{|c|}
\hline $\begin{array}{l}\text { See end of article for } \\
\text { authors' affiliations }\end{array}$ \\
\hline $\begin{array}{l}\text { Correspondence to: } \\
\text { Professor Deborah Glik, } \\
\text { UCLA School of Public } \\
\text { Health, PO Box } 951772 \\
\text { Los Angeles, CA } 90095 \\
1772 \text {, USA; dglik@ucla. } \\
\text { edu }\end{array}$ \\
\hline $\begin{array}{l}\text { Received } \\
12 \text { December } 2003 \\
\text { Accepted } 27 \text { June } 2004\end{array}$ \\
\hline
\end{tabular}

See end of article for authors' affiliations

Correspondence to: Professor Deborah Glik Health, PO Box 951772 Los Angeles, CA 900951772, USA; dglik@ucla.

Received

Accepted 27 June 2004

\begin{abstract}
Objective: The top 50 commercially successful films released per year from 1991 to 2000 were content coded to assess trends in tobacco use over time and attributes of films predictive of higher smoking rates. Design: This observational study used media content analysis methods to generate data about tobacco use depictions in films studied ( $n=497$ ). Films are the basic unit of analysis. Once films were coded and preliminary analysis completed, outcome data were transformed to approximate multivariate normality before being analysed with general linear models and longitudinal mixed method regression methods. Main outcome measures: Tobacco use per minute of film was the main outcome measure used. Predictor variables include attributes of films and actors. Tobacco use was defined as any cigarette, cigar, and chewing tobacco use as well as the display of smoke and cigarette paraphernalia such as ashtrays, brand names, or logos within frames of films reviewed.

Results: Smoking rates in the top films fluctuated yearly over the decade with an overall modest downward trend ( $p<0.005)$, with the exception of $R$ rated films where rates went up.

Conclusions: The decrease in smoking rates found in films in the past decade is modest given extensive efforts to educate the entertainment industry on this issue over the past decade. Monitoring, education, advocacy, and policy change to bring tobacco depiction rates down further should continue.
\end{abstract}

$\mathrm{T}$ he prevalence of tobacco use in popular media and its impact on youth has generated both research and advocacy over the past decade. ${ }^{1-10}$ Smoking in films is a public health concern as recent studies suggest that tobacco use in popular media influences initiation of smoking among youth. ${ }^{11-16}$ However whether tobacco use in popular films has increased, decreased, or stayed the same over the past decade is debated. Inconsistencies in the published literature on this topic are linked to methods used and movie content analysed. ${ }^{1-10}$ Findings reported depend on sample size, study time frame, data collection, coding, and data analysis, with most studies deficient on one or more of these attributes.

The Thumbs Up! Thumbs Down! (TUTD) data set is the most comprehensive data set collected on this topic, with ample sample size, adequate time frame, and reliable measurement methods. ${ }^{10}$ For this study, data from the first 10 years of the project ( 1991 to 2001) have been transformed and re-analysed using multivariate statistical techniques to examine (1) trends over time, (2) predictors of smoking in films, and (3) main and interaction effects among predictors. Use of an adequate sample, robust measures, and appropriate analytic models represent more valid methodological approaches than have been reported in comparable studies.

\section{METHODS}

The sample consists of 497 movies released between 1991 and 2001, representing the top 50 movies per year for 10 years released based on domestic box office (DBO) gross, the amount of money made by the film in the first year of release. Ratings are based on data from World Wide Box Office ${ }^{17}$ and Movies.com Box Office Report. ${ }^{18}$ Other data on movie ratings, genre, film length, leading actors, and production facts are gathered from the Internet Movie database. ${ }^{19}$ Slightly fewer than 500 films are in the final sample because of missing data.

All movies were reviewed in video format for accuracy and ease of confirmation of coded content. To assure accuracy, each movie was viewed in its entirety and coded by three reviewers. Kappa reliability scores were over 0.85 . Concordance coding, where there is agreement between coders, was used to determine final scores entered. For this media content analysis, films are the basic unit of analysis and tobacco use incidents and attributes of films the main variables coded..$^{21}$

\section{Dependent variables}

Tobacco incidents per minute are defined as total incidents of tobacco use divided by length of film in minutes. Thus 0.17 would mean that for a 120 minute film there would be approximately 21 smoking incidents or one incident for every 5-6 minutes of film.

\section{Independent variables}

Attributes of films include the year the film was released. Film ratings follow MPAA guidelines where " 1 " is G (no restrictions), "2" is PG (parental guidance), " 3 " is PG - 13 (parental guidance and children under 13 not admitted without adult companion) and " 4 " is $\mathrm{R}$ (under 17 not admitted without adult companion). For mixed model regression analyses these film ratings each were recoded to " 1 " if true or " 0 " if not true for the specific film. Genre of film is also coded in two ways. First the primary genre of film is coded in six categories where " 1 " is action/adventure, " 2 " is horror/thriller, " 3 " is drama, " 4 " is family, " 5 " is comedy, and "62 is fantasy/sci-fi. For mixed model regression analyses these film genres were each re-coded to " 1 " if true or " 0 " if not true for the specific film. Finally number of lead actors who smoke within each film was coded.

Power transformations of dependent variable of tobacco use incidents per minute were carried out using square root transformations, as distributions are positively skewed with most films having low or no smoking while a few films may have much higher rates than average. ${ }^{22}$ The general linear model technique was used to assess the relative contribution of film attributes such as year of release, rating, and genre, as predictive of the amount of smoking in the films. Then a mixed models regression analysis used a random effects

Abbreviations: DBO, domestic box office; MPAA, Motion Picture Association of America; TUTD, Thumbs Up! Thumbs Down! 
Table 1 Tobacco incidents in films by year released

\begin{tabular}{|c|c|c|c|c|c|c|}
\hline \multirow{2}{*}{$\begin{array}{l}\text { Year of release: } \\
\text { May-April } \\
\text { (no. of films) }\end{array}$} & \multicolumn{2}{|c|}{ Total tobacco incidents } & \multicolumn{2}{|c|}{ Tobacco incidents/min } & \multicolumn{2}{|c|}{$\begin{array}{l}\text { Square root tobacco } \\
\text { incidents } / \mathrm{min}\end{array}$} \\
\hline & Mean & SD & Mean & SD & Mean & SD \\
\hline 1991-92 (50) & 34.58 & 55.396 & 0.236 & 0.253 & 0.406 & 0.269 \\
\hline 1992-93 (50) & 15.64 & 20.880 & 0.131 & 0.155 & 0.286 & 0.225 \\
\hline $1993-94(50)$ & 25.24 & 33.323 & 0.196 & 0.206 & 0.364 & 0.256 \\
\hline $1994-95(50)$ & 23.72 & 31.470 & 0.183 & 0.228 & 0.332 & 0.272 \\
\hline $1995-96(50)$ & 26.14 & 61.124 & 0.150 & 0.209 & 0.286 & 0.264 \\
\hline 1996-97 (50) & 21.28 & 24.893 & 0.182 & 0.206 & 0.342 & 0.257 \\
\hline $1997-98(50)$ & 22.46 & 22.939 & 0.193 & 0.197 & 0.370 & 0.239 \\
\hline $1998-99$ (52) & 15.346 & 23.599 & 0.132 & 0.198 & 0.255 & 0.262 \\
\hline 1999-00 (50) & 15.52 & 22.964 & 0.143 & 0.233 & 0.263 & 0.275 \\
\hline 2000-01 (45) & 15.318 & 18.853 & 0.129 & 0.155 & 0.274 & 0.240 \\
\hline Average & 21.539 & 34.824 & 0.168 & 0.207 & 0.318 & 0.259 \\
\hline
\end{tabular}

model to account for the random fluctuations around the mean of the outcome variable (tobacco use incidents per minute of films) across years of the film sample. ${ }^{23}{ }^{24}$ Fixed effects represent predictors of tobacco use rates and were included in mixed models regression analyses.

\section{RESULTS}

In the TUTD data set used in this analysis, approximately $75 \%$ of films have some tobacco use. Of films with tobacco use, one third of the films had very low use (1-9 incidents), one third had moderate tobacco use (10-29 incidents), and one third (or $25 \%$ overall) had high or "problematic" rates of tobacco use (more than 30 instances). These findings are consistent with other studies.

In table 1 means and standard deviations (SD) of both transformed and untransformed variables representing average number of smoking incidents per film per year and then smoking incidents per minute of film per year are presented. In the left and middle columns of table 1 average rates of smoking per minute of film range from 0.129 in 2000-01 $($ mean $=15.34$ incidents per film or one incident every $7-8$ minutes) to 0.235 in $1991-92$ (mean $=34.58$ incidents per film or one incident every 3-4 minutes). Total incidents of smoking are included here as this measure is intrinsically meaningful but further analyses are carried out on the standardised measure of smoking incidents per minute of film. Large fluctuations between years as well as high variance around the means are seen in untransformed variables.

For the general linear models analysis with smoking incidents per minute of film as the dependent variable, there are significant effects for MPAA rating $(F=3.85, p<0.01)$, indicating more smoking for $\mathrm{R}$ rated films, and for year of release $(\mathrm{F}=2.68, \mathrm{p}<0.01)$ indicating overall smoking decreased slightly over time. One interaction effect, genre $\mathrm{X}$ year of release $(\mathrm{F}=1.44, \mathrm{p}<.05)$ was significant, as action/ adventure and drama in particular show increases in smoking over time. Based on an adjusted r-square, the overall model explains $21 \%$ of the variance in tobacco use rates, a moderate effect.

In table 2 results from analyses using longitudinal linear mixed models are presented. Model 1 uses the total sample of films from all MPAA rating categories $(n=497)$. Model 2 includes only films from G, PG and PG-13 categories ( $\mathrm{n}=289$ ), to test whether trends in youth oriented films mirror more general findings. Both models reveal a negative coefficient for rate of change indicating that over the 10 years data were collected, tobacco use in films sampled decreased, although the actual rate of decrease is modest. At the same time, positive coefficients for drama and $\mathrm{R}$ rated films for the total sample indicate that even as tobacco use in films was

Table 2 Generalised effects mixed model regression for incidents of tobacco use per minute of film (square root transformation)

\begin{tabular}{|c|c|c|c|c|c|c|}
\hline \multirow[b]{2}{*}{ Fixed effects } & \multicolumn{3}{|c|}{ Model 1 (total sample) } & \multicolumn{3}{|c|}{ Model 2 (G, PG, PG-13 films) } \\
\hline & Estimate & $t$ Value & Sig & Estimate & $t$ Value & Sig \\
\hline Rate of change & -0.011 & -2.863 & $0.004^{*}$ & -0.014 & -3.104 & $0.002^{*}$ \\
\hline Action & 0.103 & 1.486 & 0.138 & 0.102 & 1.605 & 0.11 \\
\hline Comedy & 0.048 & 0.887 & 0.376 & 0.045 & 0.937 & 0.349 \\
\hline Drama & 0.156 & 2.054 & $0.041^{*}$ & 0.154 & 2.218 & $0.027^{*}$ \\
\hline Horror & -0.149 & -0.619 & 0.536 & -0.157 & -0.714 & 0.476 \\
\hline Sci-fi & 0.139 & 1.251 & 0.212 & 0.144 & 1.415 & 0.158 \\
\hline PG-13 & -0.006 & -0.036 & 0.971 & -0.007 & -0.048 & 0.962 \\
\hline $\mathrm{R}$ rated & 0.511 & 2.122 & $0.034^{*}$ & - & - & - \\
\hline Action X PG-13 & 0.129 & 0.699 & 0.485 & 0.135 & 0.8 & 0.424 \\
\hline Action X R & -0.323 & -1.293 & 0.197 & - & - & - \\
\hline Comedy X PG-13 & 0.115 & 0.643 & 0.521 & 0.118 & 0.724 & 0.47 \\
\hline Comedy X R & -0.29 & -1.17 & 0.242 & - & - & - \\
\hline Drama X PG-13 & 0.106 & 0.556 & 0.578 & 0.112 & 0.641 & 0.522 \\
\hline Drama X R & -0.323 & -1.278 & 0.202 & - & - & - \\
\hline Horror X PG-13 & 0.29 & 0.96 & 0.337 & 0.303 & 1.101 & 0.272 \\
\hline Horror X R & -0.112 & -0.328 & 0.743 & - & - & - \\
\hline Sci-fi X PG-13 & -0.049 & -0.222 & 0.824 & -0.052 & -0.262 & 0.793 \\
\hline Sci-fi X R & -0.507 & -1.783 & 0.075 & - & - & - \\
\hline
\end{tabular}

Model $1(\mathrm{n}=497): R^{2}=0.431$ (adjusted $\left.=0.155\right)$.

Model $2(\mathrm{n}=289): R^{2}=0.40$ (adjusted $=0.12$ ).

${ }^{*} \mathrm{p}<0.05$. 


\section{What this paper adds}

To assess the issue of smoking rates in films, this paper takes a larger sample of commercially successful films and a more analytically sophisticated approach than previous papers on the subject. Both analysis of trends over time and modelling of predictive factors of smoking rates in popular movies over the past decade are reported. It is shown that smoking rates edged slightly downwards at the end of the last decade rather than increasing, the latter a common perception among anti-smoking advocates. Objective analysis of a valid data set is an important facet of advocacy work with the entertainment media to try to bring rates of tobacco use in movies down.

decreasing overall, films with these attributes had an increase in tobacco use. Translated into real rates this means that over a 10 year period, for all films considered, there was an average annual decline of 0.99 incidents of smoking per film, while for youth oriented movies there was an average annual decline of 1.26 incidents of smoking per film. The first model explains $15 \%$ of the variance in tobacco use rates. In the second model the rate of decrease is slightly higher and only the attribute of being a drama counters the overall downward trend. This model explains $12 \%$ of the variance.

Rates of tobacco use per minute of film was highly positively correlated with the number of lead actors who smoked, both for the total sample $(r=0.0 .83, \mathrm{p}<0.01$, two tailed $)$ and for youth oriented films $(r=0.81, \mathrm{p}<0.01$, two tailed). Because of the high intercorrelation between these two variables, number of lead actors was not used as an independent variable in multivariate models, in order to better understand the effects of other independent variables. Rates of smoking in films sampled were not correlated with box office gross $(r=-0.089$, NS)

\section{DISCUSSION}

Results suggest that although the rates of tobacco use in films over the past decade have declined overall, this trend is not strong. More interesting is that despite yearly fluctuations and a slight significant downward drift, rates of smoking in films have been relatively stable over the past decade. Smoking rates in $\mathrm{R}$ rated films and dramas went up over the decade. An important factor explaining why some movies have more tobacco use is the number of celebrity actors who smoke. ${ }^{25}$

These downward trends, particularly in youth oriented films, may be linked to changing norms about tobacco use, changes in policies within entertainment production companies, and possibly entertainment industry responses to antitobacco consumer demands and consumer advocacy groups. There is some evidence moreover that rates have gone back up in films released between 2001 and 2003, but whether this is a short term fluctuation or long term trend cannot be determined at this time. ${ }^{10}$

For rates to continue to decline it is important that efforts continue to be made to induce celebrities, entertainment industry professionals, and executives to work to reduce tobacco depictions on screen. Rigorous media monitoring to account for these trends also needs to continue to be supported.

\section{ACKNOWLEDGEMENTS}

Thumbs Up! Thumbs Down! is funded by the California Tobacco Tax Health Protection Act of 1988 - Proposition 99, under contract \# 00 90377 awarded by the California Department of Health Services, Tobacco Control Section. Special thanks to Deirdre Imershein (Ruffian Entertainment, Los Angeles), Larry Bloustein (American
Heart Association, Los Angeles), Larry Deutschman (Entertainment Industries Council, Los Angeles), and Melissa Havard (Pediatric Aids Foundation, Los Angeles) for insights about this issue, to Dr Abdelmonem Afifi, UCLA School of Public Health for statistical consultation, and to Dr Jeffrey Wigand (Smoke-free Kids, Inc) for feedback and encouragement on this project.

\section{Authors' affiliations}

C Mekemson, K Titus, S Mitchell, American Lung Association of Sacramento Emigrant Trails, STARS Project, Sacramento, California, USA

D Glik, A Myerson, University of California at Los Angeles, UCLA School of Public Health, Health and Media Research Group, Los Angeles, California, USA

A Shaivitz, Hollywood Health and Society, University of Southern California, Norman Lear Center, Los Angeles, California, USA A Ang, UCLA School of Medicine, Department of Internal Medicine, Los Angeles, California, USA

\section{APPENDIX}

More detailed explanations of methods and analysis can be found in the Appendix. To view the Appendix please visit the Tobacco Control website-http://www.tobaccocontrol.com/ supplemental

\section{REFERENCES}

1 Terre L, Drabman RS, Speer P. Health-relevant behaviors in the media. J Appl Soc Psychol 1991;21:1303-1319.

2 Russo- Hazan A, Liptons HL, Glantz SA. Popular films do not reflect current tobacco use. Am J Public Health 1994;84:98-1000.

3 Stockwell TF, Glantz SA. Tobacco use is increasing in popular films. Tobacco Control 1997; 6:282-4.

4 Mclntosh WD, Bazzini DG, Smith SS, et al. Who smokes in Hollywood? Characteristics of smokers in popular films from 1940 to 1989. Addict Behav 1998;23:395-98.

5 Everett SA, Schnuth RL, Tribble JL. Tobacco and alcohol use in top grossing American films. J Community Health Sci 1998;23:317-24.

6 Dalton MA, Tickle JJ, Sargent JD, et al. The incidence and context of tobacco use in popular movies from 1988 to 1997. Prev Med 2002;34:516-23.

7 Kacirk K, Glantz S. Tobacco use in movies in 2000, exceeded rates in the 1960's. Tobacco Control 2001;10:397-8.

$8 \mathrm{Ng}$ C, Drakake B. Tobacco at the movies: tobacco use in PG -13 films. Report by the Massachusetts Public Interest Research Group (MassPIRG); 2002. hHtp://www.pirg.org/tobacco [Accessed 10 Dec 2003]

9 Glantz SA, Kacirk, KW, McCulloch C. Back to the future: smoking in movies in 2002 compared with 1950 levels. Am J Public Health 2004;94:261-3.

10 American Lung Association of Sacramento. Emigrant trails - California. Tobacco use in the movies annual report card. Thumbs Up! Thumbs Down! Annual reports 1991-2003. http://www.saclung.org/thumbs/htm [Accessed 10 Dec 2003].

11 Di Stefan JM, Gilpin EA, Sargent JD, et al. Do movie stars encourage adolescents to start smoking? Evidence from California. Prev Med 1998;28:1-11.

12 Pucci LG, Siegel M. Exposure to brand- specific cigarette advertising in magazines and its impact on youth smoking. Prev Med 1999;29:313-20.

13 Sargent JD, Dalton MA, Beach ML, et al. Effect of cigarette promotions on smoking uptake in adolescents. Prev Med 2000;30:320-7.

14 Sargent JD, Beach ML, Dalton MA, et al. Effect of seeing tobacco use in films on trying smoking among adolescents: cross sectional study. BMJ $2001 ; 232: 1-6$

15 Sargent JD, Tickle JJ, Beach ML, et al. Brand appearances in contemporary cinema films and contribution to global marketing of cigarettes. Lancet 2001;357:29-32

16 Dalton MA, Sargent JD, Beach ML, et al. Effect of viewing smoking in movies on adolescent smoking initiation: a cohort study. Lancet, 2003.http:// image.thelancet.com/extras/03art1353web.pdf.

17 Worldwide Box Office, Domestic Box Office Summaries. http:// worldwideboxoffice.com, [Accessed 10 Dec 2003].

18 Movies. com Box Office Report. http://movies.go.com/boxoffice/iindex.html [Accessed 12 Feb 2004].

19 Internet Movie Data Base (IMDB). Comprehensive data on popular movies, actors, and directors. http://www.imdb.com [Accessed 10 Dec 2003].

20 Berelson B. Content analysis in communications research. New York: Free Press, 1952.

21 Krippendorff K. Content analysis: an introduction to its methodology. Beverly Hills, California: Sage Publications, 1980.

22 Fox J. Applied regression analysis, linear models, and related methods. Thousand Oaks, California: Sage Publications, 1997:60-7.

23 Neter J, Kutner MH, Wasserman W, et al. Applied linear statistical models. New York: McGraw-Hill Higher Education, 1996.

24 Verbeke G, Molenberghs G. Linear mixed models for longitudinal data. New York: Springer Verlag, 2000

25 Mekemson C, Glantz SA. How the tobacco industry built its relationship with Hollywood. Tobacco Control 2002;11(suppl I):i81-91. 